\title{
Warning systems as social processes for Bangladesh cyclones
}

Ilan Kelman

UCL Institute for Risk \& Disaster Reduction, UCL Institute for Global Health, and University of Agder

Wilkins Building - South Wing, Gower Street, London, WC1E 6BT, UK

ilan_kelman@hotmail.com

Bayes Ahmed

UCL Institute for Risk \& Disaster Reduction and UCL Humanitarian Institute

Wilkins Building - South Wing, Gower Street, London, WC1E 6BT, UK

bayesahmed@gmail.com

Md. Esraz-Ul-Zannat

Department of Urban \& Regional Planning (URP), Khulna University of Engineering \& Technology (KUET), Khulna-9203, Bangladesh

esraz@urp.kuet.ac.bd

Md. Mustafa Saroar

Department of Urban \& Regional Planning (URP), Khulna University of Engineering \& Technology (KUET), Khulna-9203, Bangladesh

saroar.mustafa@yahoo.com

Maureen Fordham

UCL Institute for Risk \& Disaster Reduction and Gender and Disaster Network

Wilkins Building - South Wing, Gower Street, London, WC1E 6BT, UK

m.fordham@ucl.ac.uk

Mohammad Shamsudduha

UCL Institute for Risk \& Disaster Reduction

Wilkins Building - South Wing, Gower Street, London, WC1E 6BT, UK

m.shamsudduha@ucl.ac.uk

\section{Abstract}

Purpose: This article connects the theoretical idea of warning systems as social processes with empirical data of people's perceptions of and actions for warning for cyclones in Bangladesh.

Design/methodology/approach: A case study approach is used in two villages of Khulna district in southwest Bangladesh: Kalabogi and Kamarkhola. Sixty households in each village were surveyed with structured questionnaires regarding how they receive their cyclone warning information as well as their experiences of warnings for Cyclone Sidr in 2007 and Cyclone Aila in 2009.

Findings: People in the two villages had a high rate of receiving cyclone warnings and accepted them as being credible. They also experienced high impacts from the cyclones. Yet evacuation rates to cyclone shelters were low. They did not believe that significant cyclone damage would affect them and they also highlighted the difficulty of getting to cyclone 
shelters due to poor roads, leading them to prefer other evacuation options which were implemented if needed.

Originality/value: Theoretical constructs of warning systems, such as the First Mile and late warning, are rarely examined empirically according to people's perceptions of warnings. The case study villages have not before been researched with respect to warning systems. The findings provide empirical evidence for long-established principles of warning systems as social processes, usually involving but not relying on technical components.

\section{Keywords}

Bangladesh, cyclone vulnerability, storms, warning process, warning system

\section{Article classification}

Case study

\section{Introduction}

Bangladesh is frequently labelled as one of the most disaster-prone countries (e.g. Khan, 2008; Shahid and Behrawan, 2008) but it is also touted as being a good practice example for cyclone warning and evacuation (e.g. Akhand, 2003; Haque et al., 2012; Mallick et al., 2011). This explanation is framed through declining disaster mortality despite increasing population numbers: a 1970 cyclone killed at least 224,000 people (Sommer and Moseley, 1972), Cyclone Gorky in 1991 killed approximately 140,000 people (Paul, 2009), and then Cyclone Sidr in 2007 killed 3,406 people (Paul, 2009) followed by Cyclone Aila in 2009 killing about 190 people (Saha, 2015). The cyclone death toll reduction is attributed to a system in which villages are warned of impending cyclones through community-based efforts followed by evacuating to shelters which are integrated into the community.

Although communities are never homogenous and some households and communities always have fewer options than others (Cannon, 2007), Bangladesh's community-based efforts differ from assumptions in much literature about the nature of warning systems. The traditional scientific structure of warning systems is top-down. External institutions provide information about an impending hazard followed by command-and-control instructions directing response. Any previous training and drills are selected, designed, and organised externally.

Research, policy, and practice has challenged this construct, from evidence regarding the importance of unofficial warnings (Parker and Handmer, 1998) to the United Nations' people-centred warning systems (Basher, 2006). As illustrated by these studies respectively, most publications countering the top-down view of warning systems are either empirical or theoretical. Few interpret people's perceptions of and actions for warning in the context of theories of warning systems as social processes - despite some foundational work (e.g. Mileti et al., 1975) pushing for this agenda.

This article contributes to warning systems literature through case studies in Khulna district in southwest Bangladesh where people have been affected by cyclones and provide their experiences of warning systems. It provides further originality in that the locations selected have not before been studied with respect to warning systems, although some wide-scale 
studies on cyclone warning and evacuation (e.g. Saha, 2017; Saha and James, 2017) encompass southwest Bangladesh within their data.

\section{Fieldwork}

Khulna, Bangladesh sits at approximately $22.9^{\circ} \mathrm{N}$ and $89.5^{\circ} \mathrm{E}$ and experiences numerous cyclones. Due to local topographic and societal differences, coastal locations can undergo highly differentiated impacts from the same storm. Research was conducted in two villages in Dacope Upazila, Khulna: Kalabogi and Kamarkhola (Figure 1).
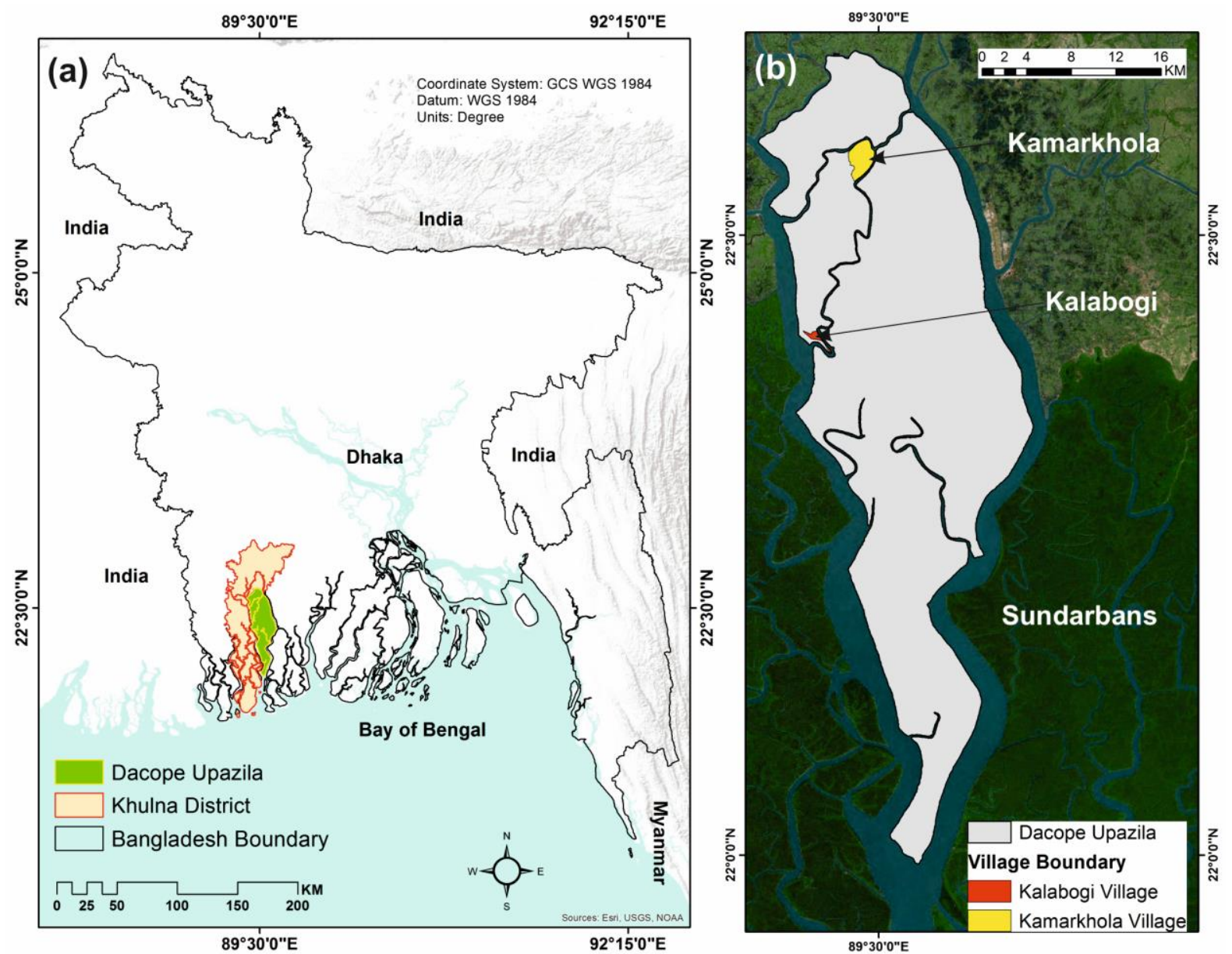

Figure 1. Location of (a) Khulna district in Bangladesh, and (b) Kalabogi and Kamarkhola villages in Dacope Upazila.

All of Kalabogi (also known as Jhulantapara) is directly exposed to wind and water from cyclones. Most of the 480 households (average family size is 5) sit along the River Shibsha, so they experience loss of land and they frequently move as the river shifts its course. Their livelihoods are mostly fishing, as their settlement is surrounded on three sides by rivers and the Sundarban mangroves. Kamarkhola village is less exposed to the water from cyclones, as it is sited away from waterways and is divided by a road serving as an embankment. Kamarkhola has around 375 households (average family size is 4) which depend mainly on traditional crop agriculture for livelihoods. Kamarkhola's villagers enjoy better access to health, education, markets, and administrative services than Kalabogi's. 
Both villages were affected by Sidr and Aila. Sidr damaged mainly trees and houses, while Aila also impacted livelihoods because areas in and around the villages were inundated with saltwater which hampered rice cultivation and interfered with freshwater fishing. In Kamarkhola, the area behind the road/embankment was not subject to saltwater contamination, whereas all other areas were submerged, severely damaging infrastructure. No fatalities were reported in either village from either cyclone.

In each village, 60 randomly selected households were surveyed in July and August 2017 with structured questionnaires regarding how they receive their cyclone warning information as well as their experiences of warnings for Sidr and Aila. The surveys were conducted in the local language by teams of men and women from Khulna. The data were analysed using SPSS software (v.25).

Because these villages had not before been studied, pre-Sidr comparative data are not available. Additionally, the surveys are premised on people accurately remembering how they acted and being truthful. Given the household level at which the surveys were conducted, respondents might assume that their answers would be known to others, or desire this, so they could respond according to what they would want their neighbours to know. Finally, the random sampling might have missed marginalised individuals who would be in most need of warning and evacuation support.

\section{Results}

Tables 1-4 indicate warning, evacuation, and post-cyclone impacts in the villages for Sidr and Aila. The high rate of timely warnings received contrasts with the low rate of evacuation and the long period of post-cyclone impacts. Those who received warnings but did not go to shelters indicated that it is a deliberate choice. Despite previous cyclone experiences, they did not expect significant cyclone damage to affect them and they also highlighted the difficulty of getting to cyclone shelters due to poor roads. Even the worst case of complete inundation of the village would permit them to reach high land by swimming to an embankment, which they did, with little concern about potential dangers, such as flowing water, dirty water, debris, snakes, inability to swim, fatigue, darkness, and hypothermia. The extensive postcyclone impacts experienced after Sidr and Aila did not appear to influence this attitude of not needing to evacuate, although Table 2 does show increases in evacuation rates for Aila just 18 months after Sidr. The reason stated was mainly the higher impacts, as noted above, especially in terms of Kamarkhola flooding which led many more people to shelter on the embankment.

Table 1: Percent of respondents receiving timely warning for Sidr and Aila

\begin{tabular}{||l|l|l|}
\cline { 2 - 3 } \multicolumn{1}{c|}{} & Kalabogi & Kamarkhola \\
\hline \hline Sidr & $78 \%$ & $60 \%$ \\
\hline Aila & $87 \%$ & $68 \%$ \\
\hline
\end{tabular}

Table 2: Percent of respondents evacuating to a safe place for Sidr and Aila

\begin{tabular}{|l||l|l|l||l|l|l||}
\hline \hline \multirow{2}{*}{} & \multicolumn{3}{|c|}{ Kalabogi } & \multicolumn{3}{c||}{ Kamarkhola } \\
\cline { 2 - 7 } & $\begin{array}{l}\text { Cyclone } \\
\text { shelter }\end{array}$ & $\begin{array}{l}\text { Neighbour's } \\
\text { safe house }\end{array}$ & Embankment & $\begin{array}{l}\text { Cyclone } \\
\text { shelter }\end{array}$ & $\begin{array}{l}\text { Neighbour's } \\
\text { safe house }\end{array}$ & Embankment \\
\hline Sidr & $22 \%$ & $5 \%$ & $10 \%$ & $7 \%$ & $5 \%$ & $17 \%$ \\
\hline Aila & $27 \%$ & $7 \%$ & $15 \%$ & $12 \%$ & $8 \%$ & $48 \%$ \\
\hline
\end{tabular}


Table 3: Post-cyclone impacts for Sidr and Aila in Kalabogi

\begin{tabular}{|l|l|l|l||}
\hline \multicolumn{1}{|c|}{ Post-Sidr } & \multicolumn{1}{|c|}{$\begin{array}{c}\text { Average } \\
\text { time period }\end{array}$} & \multicolumn{1}{|c|}{ Post-Aila } & \multicolumn{1}{|c|}{$\begin{array}{c}\text { Average time } \\
\text { period }\end{array}$} \\
\hline Stayed on embankment & 11 days & Stayed on embankment & 61 days \\
\hline Stayed outside of own residence & 11 days & $\begin{array}{l}\text { Stayed outside of own } \\
\text { residence }\end{array}$ & 64 days \\
\hline $\begin{array}{l}\text { Dependent on external } \\
\text { assistance/relief }\end{array}$ & 1.5 months & $\begin{array}{l}\text { Dependent on external } \\
\text { assistance/relief }\end{array}$ & 4.7 months \\
\hline To fully recover economically & 10 months & To fully recover economically & 31 months \\
\hline
\end{tabular}

Table 4: Post-cyclone impacts for Sidr and Aila in Kamarkhola

\begin{tabular}{|l|l|l|l||}
\hline \multicolumn{1}{|c|}{ Post-Sidr } & \multicolumn{1}{|c|}{$\begin{array}{c}\text { Average } \\
\text { time period }\end{array}$} & \multicolumn{1}{|c|}{ Post-Aila } & \multicolumn{1}{|c|}{$\begin{array}{c}\text { Average time } \\
\text { period }\end{array}$} \\
\hline Stayed on embankment of own & 11 days & Stayed on embankment & 73 days \\
\hline $\begin{array}{l}\text { Stayed outside of } \\
\text { residence }\end{array}$ & $\begin{array}{l}\text { Stayed outside of own } \\
\text { residence }\end{array}$ & 138 days \\
\hline $\begin{array}{l}\text { Dependent on external } \\
\text { assistance/relief }\end{array}$ & 1.2 months & $\begin{array}{l}\text { Dependent on external } \\
\text { assistance/relief }\end{array}$ & 17 months \\
\hline To fully recover economically & 9.2 months & To fully recover economically & 28 months \\
\hline
\end{tabular}

Tables 5-6 provide the population's cyclone warning sources. In both villages, receiving multiple information sources is common and media are by far the most popular source, with internet not listed because households are typically not online. For Kalabogi, the next most popular sources are word-of-mouth, coming from friends and relatives as well as the mosque. The formal cyclone warning systems are least informative, mainly due to the village's remoteness, poor transport accessibility, and the lack of personnel to cover all villages. Kamarkhola displayed some differences from Kalabogi, where formal programmes matched more closely with word-of-mouth.

Table 5: Sources of cyclone warnings

(Respondents could select more than one answer.)

\begin{tabular}{|l|l|l|}
\cline { 2 - 3 } \multicolumn{1}{l|}{} & Kalabogi & Kamarkhola \\
\hline Cyclone Preparedness Program Volunteers & $9 \%$ & $20 \%$ \\
\hline NGO personnel & $14 \%$ & $40 \%$ \\
\hline Union Disaster Management Committee & $2 \%$ & $13 \%$ \\
\hline Radio/TV/newspaper & $62 \%$ & $77 \%$ \\
\hline Friends/relatives & $29 \%$ & $20 \%$ \\
\hline Mosque's loudspeaker & $26 \%$ & $47 \%$ \\
\hline
\end{tabular}

Table 6: Number of sources from which cyclone warnings are received

\begin{tabular}{|c||l|l||}
\hline Number of sources for received warnings & Kalabogi & Kamarkhola \\
\hline \hline 0 & $32 \%$ & $2 \%$ \\
\hline 1 & $20 \%$ & $12 \%$ \\
\hline 2 & $28 \%$ & $53 \%$ \\
\hline 3 & $20 \%$ & $33 \%$ \\
\hline
\end{tabular}


Warning systems require pre-warning awareness and preparedness programmes. Otherwise, people might not recognise a warning signal and might not know how to act in response to warning information. Cyclone awareness and preparedness programmes for the two villages are listed in Tables 7 and 8. Formal training and workshops reached the most people followed by popular entertainment, with a minority in each village going through more than one programme. Other means, including door-to-door efforts and using communal outdoor spaces, had the least reach. These results indicate the importance of using more than one means to reach people in order to cover as many households as possible. Formalised methods through education and arts appear to reach more people than informal or targeted approaches.

Table 7: Participation in cyclone awareness and preparedness programmes

(Respondents could select more than one answer.)

\begin{tabular}{||l|l|l||}
\cline { 2 - 3 } \multicolumn{1}{c|}{} & Kalabogi & Kamarkhola \\
\hline Training/workshop & $44 \%$ & $88 \%$ \\
\hline Mock drill & $2 \%$ & $2 \%$ \\
\hline Outdoors session & $4 \%$ & $3 \%$ \\
\hline Door-to-door campaign & $0 \%$ & $12 \%$ \\
\hline Entertainment: video, theatre, music & $21 \%$ & $40 \%$ \\
\hline Warning signal/flag display & $5 \%$ & $17 \%$ \\
\hline
\end{tabular}

Table 8: Number of cyclone awareness and preparedness programmes attended (Columns do not add up to $100 \%$ due to rounding.)

\begin{tabular}{|c||l||l||}
\hline Number of programmes & Kalabogi & Kamarkhola \\
\hline \hline 0 & $37 \%$ & $3 \%$ \\
\hline 1 & $50 \%$ & $50 \%$ \\
\hline 2 & $12 \%$ & $28 \%$ \\
\hline $3+$ & $2 \%$ & $18 \%$ \\
\hline
\end{tabular}

\section{Discussion}

The highly lauded cyclone warning and shelter system across Bangladesh (Akhand, 2003; Haque et al., 2012; Mallick et al., 2011), notwithstanding other factors lowering cyclone mortality such as coastal ecosystem management (Haque et al., 2012; Paul, 2009), is further indicated by the fieldwork here in small, isolated villages. Yet a significant proportion of the population surveyed does not receive cyclone warnings through formal channels, even though the formal awareness and preparedness programmes had significant reach. Meanwhile, a large part of the population would not necessarily evacuate to shelters because they are not concerned about cyclone-related threats to life. These results indicate the importance of people developing and applying their own warning and evacuation systems for hazards. Even accepted external interventions might not be as effective as internal initiatives.

The fieldwork highlights the importance of several aspects underlying warning systems as social processes. In contrast to previous findings (Haque and Blair, 1992; Haque et al., 2012; Paul, 2012; Paul and Dutt, 2010; Paul et al., 2010; Saha and James, 2017), the lack of evacuation to shelters in these two villages was not stated as being due to poor or untrusted warning communication, widespread concerns about the shelters, worry about possessions, or specific demographic groups in the population. Instead, the people surveyed-hampered by poor road access to reach the shelters and some concerns about safety and dignity in the 
shelters - perceived that they would manage on their own, which would include moving to a neighbour's safer building or to an embankment.

This strategy did not lead to recorded fatalities for Sidr or Aila in the case study villages. This success might extend to future cyclones - or might lead to large numbers of deaths. The key is examining whether or not the warning system serves local needs across multiple scenarios.

For serving local needs, 'The First Mile' for warning systems should be considered for implementation. This approach re-defines 'The Last Mile' principle of warning systems being about conveying the right information to the right people in the right way at the right time, thereby making warnings timely and effective. Providing such information does not begin when a hazard manifests, but would be integrated into ongoing, day-to-day development and actions. 'The right time' for warning information in a First Mile warning system is now and every day, with 'the right information' being a continual process of exchanging and understanding environmental and societal characteristics. A warning system is not a one-off spurt of material, based on a single hazard, which then stops until the next hazard appears. Instead, preparation and awareness need to be integrated into daily lives, not as an extra item or separate task, so that no specific hazard warning information (as part of the overall warning system) becomes surprising. Consequently, as part of the warning system, people would know how to generate their own warning information and how to respond to any given warning.

This approach means 'in the right way' by starting with the people and their needs, which was a pertinent lesson following appropriate warnings and inadequate evacuation for the 1991 cyclone affecting Bangladesh (Haque, 1995). As the fieldwork here demonstrated, certain mechanisms for preparedness and awareness dominate as do certain sources for specific warning information. These mechanisms and sources should be emphasised alongside consideration given to who is not reached by them and why.

$2 \%$ of households in Kalabogi were reached by the Union Disaster Management Committee. This figure does not mean that the committee should be abolished, if those $2 \%$ have no other source of warning or if those $2 \%$ are the most marginalised households - given that 'the right people' means everyone. People have different needs and many would prefer to be reached by more than one source for contingency. 'In the right way' means continuing to understand how warning information is generated and received, enhancing successful pathways, filling in gaps, paying attention to changes in the locations and the people, and being flexible and dynamic.

A similar ethos applies to evacuation. Were the people surveyed blasé or naïve for not evacuating to cyclone shelters? Yet the lack of reported mortality during Sidr and Aila indicates that the system has benefits. This situation does not mean that nothing could go wrong in the future. Additionally, care is needed to factor in more than just immediate mortality; for instance, morbidity, malnutrition, sexual assault, and long-term deaths. Working with the villagers would help to determine how dangerous different situations could be for people who do and do not evacuate to shelters. If people are resolute about not leaving, then strengthening sheltering-in-place might bring benefits. A co-design model would best meet the needs and interests of all the villagers, again emphasising that no community is homogenous (Cannon, 2007). 
The First Mile for warning systems encompasses all these aspects, contrasting with The Last Mile which tends to view warning systems as being top-down and technology-based. In the Last Mile, a technical system is created for monitoring hazards and preparing messages, so the Last Mile is the final step of disseminating the top-down messages to people who are expected to obey what the messages advise. The First Mile makes no assumptions about what the people want or need from a warning system. It develops a long-term, continuous warning system based on the people's articulated and changing interests, knowledge, technology, and expertise, all balanced with needed support and supplements from external knowledge, technology, and expertise.

For instance, the two villages here could potentially be affected by tsunamis, some of which would originate too far away to notice the trigger, such as an earthquake, volcanic eruption, landslide, or meteorite strike. In these cases, rapid dissemination of external, technical knowledge of a coming wave would be essential as part of the warning system. Without prior involvement by the people, it is unclear how these messages would have credibility or if appropriate action would be taken by everyone. The warning system's core is that the villagers would be involved in regularly teaching and updating themselves about tsunamis, indicating what message(s) they would wish to receive and how, and practising response actions. The process of developing, implementing, and maintaining the warning system is as important as the specific products of monitoring hazards and sending messages.

These specific products, typically technological, should remain part of warning systems, with the people's support. Tsunami warning systems for the villages here would need real-time regional geological monitoring, ocean buoys, and telemetered data, as per the Indian Ocean Tsunami Warning System. For another hazard, given Bangladesh's propensity for damaging earthquakes (Steckler et al., 2016), emulating components of automatic earthquake warning systems such as in Mexico, Taiwan, and Turkey (Allen et al., 2009) could be useful, with the people's support. Warning systems as social processes do not eliminate local or external technological products. They use technology within the social contexts to which it applies without relying on it entirely, meaning that any tsunami or earthquake warning systems would need to start by working with the people in the villages, the First Mile approach, rather than starting with the technical system, the Last Mile approach.

Warning systems as social processes promote diversity in implementation, which is needed as demonstrated by the variety of sources through which the villagers surveyed receive cyclone warnings. Deeper understanding of the gamut of information sources which people seek and desire for warnings, alongside the frequently expressed need to confirm information before acting, are part of the warning system research agenda (Phillips and Morrow, 2007). This need is further corroborated by this study.

Another dimension of warning systems as social processes relates to the time scale for warning information. Much work presumes the need for warning systems which are 'early' (e.g. Basher, 2006). Kelman and Glantz (2014) challenge the standard notion of early warning systems (EWS). They query the meaning of 'early' (which must be contextual), point to research which indicates that providing too much advance notice can lead to complacency, and raise examples where early warning might not be feasible; for instance, flash floods and near-shore tsunamis with mere minutes of lead time. Earthquakes provide perhaps seconds of warning time, which is long enough to get underneath a sturdy piece of furniture (if the room has this available and if it is certain that the structure will not collapse), to move away from cooking stoves, and to shield a child. 
For this study, cyclones typically provide several days of warning with prospects for describing the wind, storm surge, and rainfall parameters expected in each village in advance of a cyclone's landfall. Given the population's acceptance of the external warning information coupled with reticence to evacuate, could several days be too much warning time? For people living at subsistence level, much of their day is focused on food and water. Extended or frequent activities requiring warning response could conflict with daily life and livelihoods. They might prefer 2, 12, 24, or (for deep-sea fishers) 72 hours' notice- or a specific warning only when it is clear which areas will be flooded, irrespective of the leadtime. By then, their local knowledge might have already alerted them to a cyclone in the vicinity, meaning that perhaps more technical information for late warning would be more useful than evacuation suggestions as part of early warning. Nothing here is certain; the people's input and direction is essential as part of an ongoing process of a warning system.

A social warning system as a continuing process covers all time scales, using a variety of information sources and messaging mechanisms - both internal and external to the locationto reach all the people in a manner amenable to their needs. This approach could potentially incorporate regular entertainment and drills for education at the beginning of each cyclone season; combinations of external systems and local environmental knowledge; word-ofmouth once a cyclone forms with a track heading towards their village; and specific statements combining internal and external knowledge of areas imminently flooding to encourage evacuation to shelters (or elsewhere). Whether or not these items would be the most expected and effective requires further consultation with the people. The proposition here is one example of how to develop an integrated, respected, First Mile warning system, which integrates aspects of, but does not rely entirely on, a technocratic construction invoked externally once a specific cyclone's probable track has been calculated. The key is to use multiple approaches simultaneously.

\section{Conclusion}

Examining warning systems as social processes through cyclone experiences in isolated Bangladeshi villages has reaffirmed the importance of contextuality. A single route and form for warning information cannot meet everyone's needs, yet the point of a warning system is to ensure that everyone is included. Therefore, multiple channels, mechanisms, and approaches are required to be fully inclusive. As the evidence here illustrates, even with apparently accepted, accurate, and desired warning information from trusted sources, people will not necessarily continue the warning process (as it was designed) by evacuating and using cyclone shelters. This situation is not necessarily detrimental, but the consequences need to be made explicit.

Additionally, not all experiences and lessons are necessarily transferable, even to similar villages around coastal Bangladesh. As noted earlier, the literature provides multiple reasons why people have not always evacuated to cyclone shelters along Bangladesh's coast, even with warnings. Those reasons did not appear to the same extent in this study's fieldwork. Determining local contexts, interests, and needs supports a locally effective warning system across locations.

These findings reinforce what has long been described with regards to warning systems (Anderson, 1969; Gruntfest et al., 1978; Mileti, 1975), indicating that the long-established warning system characteristics remain apposite, including being transparent, integrated, 
trusted, continual, flexible, clearly signed and signposted, and timely, along with variations of these terms and concepts. Enacting these characteristics produces warning systems which are part of the villages, developed with and by the people, rather than being constructed and imposed by external agencies or governments on a "community". Warning systems should not compete with day-to-day life and livelihoods, but should be enfolded within them. The evidence from two previously unstudied locations in Bangladesh with respect to cyclones supports these traits, indicating that the principles of warning systems are robustly understood, yet challenges remain in applying these principles.

\section{References}

Akhand, M.H. (2003), "Disaster management and cyclone warning system in Bangladesh", in Zschau, J. and Küppers, A.N. (Eds.), Early warning systems for natural disaster reduction, Springer, Berlin, pp. 49-64.

Allen, R.M., Gasparini, P., Kamigaichi, O. and Böse, M. (2009), "The Status of Earthquake Early Warning around the World: An Introductory Overview", Seismological Research Letters, Vol. 80 No. 5, pp. 682-693.

Anderson, W.A. (1969), "Disaster warning and communication processes in two communities", The Journal of Communication, Vol. 19, pp. 92-104.

Basher, R. (2006), "Global early warning systems for natural hazards: systematic and peoplecentred”, Philosophical Transactions of the Royal Society A, Vol. 364, pp. 2167-2182.

Cannon, T. (2007), "Reducing People's Vulnerability to Natural Hazards: Communities and Resilience", Paper presented at the WIDER Conference on Fragile States-Fragile Groups: Tackling Economic and Social Vulnerability, Helsinki.

Gruntfest, E.C., Downing, T.E. and White, G.F. (1978), "Big Thompson flood exposes need for better flood reaction system to save lives", Civil Engineering, February, pp. 72-73.

Haque, C.E. (1995), "Climatic Hazards Warning Process in Bangladesh Experience of, and Lessons from, the 1991 April Cyclone", Environmental Management, Vol. 19 No. 5, pp. 719734.

Haque, C.E. and Blair, D. (1992), "Vulnerability to tropical cyclones: evidence from the April 1991 cyclone in coastal Bangladesh”, Disasters, Vol. 16 No. 3, pp. 217-229.

Haque, U., Hashizume, M., Kolivras, K.N., Overgaard, H.J., Das, B. and Yamamoto, T. (2012), "Reduced death rates from cyclones in Bangladesh: what more needs to be done?", Bulletin of the World Health Organisation, Vol. 90, pp. 150-156.

Kelman, I. and Glantz, M.H. (2014), "Early Warning Systems Defined", in Zommers, Z. and Singh, A. (Eds.), Reducing Disaster: Early Warning Systems for Climate Change, Springer, London, pp. 89-108.

Khan, M.S.A. (2008), "Disaster preparedness for sustainable development in Bangladesh", Disaster Prevention and Management, Vol. 17 No. 5, pp. 662-671. 
Mallick, B., Rahaman, K.R. and Vogt, J. (2011), "Social vulnerability analysis for sustainable disaster mitigation planning in coastal Bangladesh", Disaster Prevention and Management, Vol. 20, pp. 220-237.

Mileti, D.S. (1975), Natural Hazard Warning Systems in the United States: A Research Assessment. Institute of Behavioral Science, University of Colorado, Boulder.

Mileti, D.S., Drabek, T.E. and Haas, J.E. (1975), "Human systems in extreme environments: a sociological perspective", Monograph No. 21, Institute of Behavioral Science, University of Colorado Boulder.

Parker, D.J. and Handmer, J.W. (1998), "The Role of Unofficial Flood Warning Systems", Journal of Contingencies and Crisis Management, Vol. 6 No. 1, pp. 45-60.

Paul, B.K. (2009), "Why relatively fewer people died? The case of Bangladesh's Cyclone Sidr”, Natural Hazards, Vol. 50 No, 2, pp. 289-304.

Paul, B.K. (2012), "Factors Affecting Evacuation Behavior: The Case of 2007 Cyclone Sidr, Bangladesh", The Professional Geographer, Vol. 64 No. 3, pp. 401-414.

Paul, B.K. and Dutt, S. (2010), "Hazard Warnings and Responses to Evacuation Orders: The Case of Bangladesh's Cyclone Sidr”, Geographical Review, Vol. 100 No. 3, pp. 336-355.

Paul, B.K., Rashid, H., Islam, M.S. and Hunt, L.M. (2010), "Cyclone evacuation in Bangladesh: Tropical cyclones Gorky (1991) vs. Sidr (2007)”, Environmental Hazards, Vol. 9 No. 1, pp. 89-101.

Phillips, B.D. and Morrow, B.H. (2007), "Social Science Research Needs: Focus on Vulnerable Populations, Forecasting, and Warnings", Natural Hazards Review, Vol. 8, pp. 61-68.

Saha, C.K. (2015), "Dynamics of disaster-induced risk in southwestern coastal Bangladesh: an analysis on tropical Cyclone Aila 2009", Natural Hazards, Vol. 75 No. 1, pp. 727-754.

Saha, C.K. (2017), "Cyclone Aila, livelihood stress, and migration: empirical evidence from coastal Bangladesh”, Disasters, Vol. 41 No. 3, pp. 505-526.

Saha, S.K. and James, H. (2017), "Reasons for non-compliance with cyclone evacuation orders in Bangladesh", International Journal of Disaster Risk Reduction, Vol. 21, pp. 196204.

Shahid, S. and Behrawan, H. (2008), "Drought risk assessment in the western part of Bangladesh", Natural Hazards, Vol. 46, pp. 391-413.

Sommer, A. and Mosley, W.H. (1972), "East Bengal cyclone of November, 1970: epidemiological approach to disaster assessment", The Lancet, Vol. 299, pp. 1029-1036.

Steckler, M.S., Mondal, D.R., Akhter, S.H., Seeber, L., Feng, L., Gale, J., Hill, E.M. and Howe, M. (2016), "Locked and loading megathrust linked to active subduction beneath the Indo-Burman Ranges", Nature Geoscience, Vol. 9, pp. 615-618. 